$\int \mid$\begin{tabular}{c} 
JURNAL MEGA AKTIVA \\
Email : megaaktiva@febi.umkendari.ac.id \\
Website : https://megaaktiva.umkendari.ac.id/index.php/Jurnal \\
\hline
\end{tabular}

\title{
TATA CARA PENAGIHAN PAJAK DENGAN SURAT TEGURAN, SURAT PAKSA, SITA DAN LELANG DI KPP PRATAMA JAKARTA SAWAH BESAR SATU
}

\author{
${ }^{1}$ Eka Pujianthi \\ ${ }^{1}$ Fakultas Ekonomi dan Bisnis, Universitas Trisakti
}

\begin{abstract}
The purpose of this research is to determine the procedure of tax collection with letter of reprimand and letter of compulsion at KPP Pratama Jakarta Sawah Besar Satu. This type of method used in this research is qualitative descriptive. The data used in this research is the disbursement of tax arrears, tax arrears disbursement targets, the receipt with letter of reprimand, letter of compulsion seizure and auction for the period 2012-2015. The data were obtained from interview and documentation. The results of this research indicate that procedure of tax collection with letter of reprimand, and letter of compulsion at KPP Pratama Jakarta Sawah Besar Satu in accordance with Act No. 19 of 2000 about tax collection with letter of compulsion.
\end{abstract}

Keywords : Tax Debt, Tax Collection, Letter of Reprimand, Letter of Compulsion, Seizure and Auction

\section{PENDAHULUAN}

Di Indonesia pajak merupakan salah satu penerimaan kas negara yang memiliki peranan penting dalam pembangunan negara. Kontribusi penerimaan pajak terhadap penerimaan negara diharapkan semakin meningkat dari tahun ke tahun seiring dengan menurunnya peranan minyak dan gas bumi terhadap penerimaan negara. Penagihan pajak merupakan serangkaian tindakan agar Penanggung Pajak melunasi utang pajak dan biaya penagihan pajak dengan menegur atau memperingatkan, melaksanakan penagihan seketika dan sekaligus, memberitahukan Surat Paksa, mengusulkan pencegahan, melaksanakan penyitaan, melaksanakan penyanderaan, serta menjual barang yang telah disita. Tujuan penagihan pajak dalam instansi pemerintahan adalah untuk menjaga kestabilan pendapatan negara.

Motivasi dalam penelitian ini adalah untuk mengetahui tata cara pelaksanaan penagihan pajak aktif di KPP Pratama Jakarta Sawah Besar Satu. Tujuan penelitian ini adalah untuk mengetahui tata cara pelaksanaan penagihan pajak aktif, kesesuaian pelaksanaan penagihan pajak aktif yang dilakukan terhadap UU No. 19 tahun 2000, seberapa besar kontribusi penagihan pajak aktif dengan surat teguran, surat paksa, surat sita dan lelang terhadap pencairan tunggakan pajak, kendala dan upaya penagihan pajak aktif.

Penelitian ini disusun dengan sistematika penulisan sebagai berikut: pertama, pendahuluan yang menjelaskan latar belakang penelitian, masalah penelitian, tujuan dan manfaat penelitian, serta sistematika penulisan. Kedua, kerangka teoritis tentang penagihan pajak aktif. Ketiga, metode penelitian yang terdiri dari bentuk penelitian, objek penelitian, teknik pengumpulan data dan metode analisis data. Keempat, hasil penelitian berisi data surat teguran, surat paksa, surat sita dan lelang serta hasil wawancara. Terakhir, 


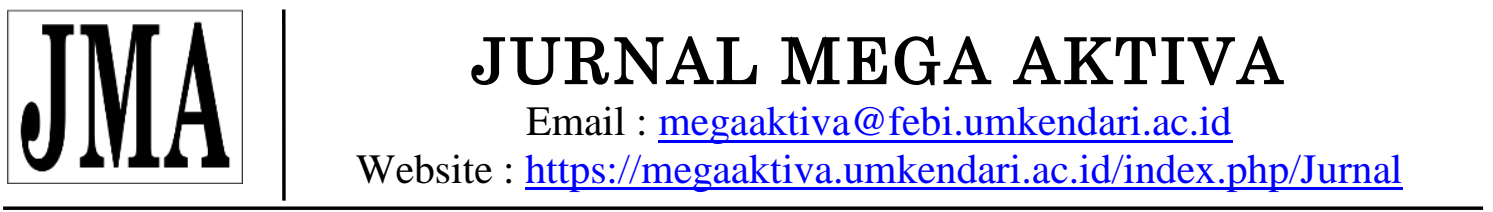

penutup yang berisi kesimpulan, keterbatasan penelitian dan rekomendasi untuk peneliti selanjutnya.

\section{KAJIAN TEORITIS}

\section{Pajak}

Dalam Undang-Undang Dalam Undang-Undang Nomor 16 Tahun 2009 tentang Perubahan Ketiga atas Undang-Undang Nomor 6 Tahun 1983 tentang Ketentuan Umum dan Tata Cara Perpajakan (KUP) tertulis bahwa Pajak adalah kontribusi Wajib Pajak kepada negara yang terutang oleh orang pribadi atau badan yang bersifat memaksa berdasarkan undang-undang dengan tidak mendapatkan imbalan secara langsung dan digunakan untuk keperluan negara bagi sebesar-besarnya kemakmuran rakyat.

Definisi pajak menurut Adriani dalam Widyaningsih $(2013,2)$ bahwa pajak adalah iuran kepada negara (dapat dipaksakan) yang terutang oleh yang wajib membayarnya menurut peraturan-peraturan dengan tidak mendapat prestasi kembali yang langsung dapat ditunjuk dan yang gunanya adalah untuk membiayai pengeluaran-pengeluaran umum berhubungan dengan tugas negara untuk menyelenggarakan pemerintahan.

Sedangkan menurut Soemitro (Mardiasmo 2013, 1) bahwa pajak adalah iuran rakyat kepada kas negara berdasarkan undang-undang (yang dapat dipaksakan) dengan tiada mendapat jasa timbal (kontraprestasi) yang langsung dapat ditunjukan dan yang digunakan untuk membayar pengeluaran umum.

Secara garis besar ciri-ciri yang terdapat pada pajak adalah sebagai berikut:

1. Pemungutan pajak dapat dipaksakan karena didasarkan atas undang-undang.

2. Pihak yang membayar pajak tidak mendapat kontraprestasi langsung.

3. Pajak dipungut oleh negara, baik oleh pemerintah pusat maupun pemerintah daerah.

4. Pajak digunakan untuk membiayai pengeluaran-pengeluaran pemerintah, dimana jika terjadi kelebihan (surplus) maka akan dipergunakan untuk membiayai public investment.

Fungsi pajak ada dua, (Mardiasmo 2013, 1) yaitu:

1. Fungsi Penerimaan (budgetair)

2. Fungsi Mengatur (regulerend)

Sistem pemungutan pajak dibagi menjadi 3 jenis (Sumarsan 2015, 14) yaitu:

1. Official Assessment System

2. Self Assessment System

3. Withholding System

Menurut Susanto $(2014,3)$ pemungutan pajak harus memenuhi syarat-syarat sebagai berikut:

1. Pemungutan pajak harus adil (Syarat Keadilan)

Pajak juga memiliki tujuan untuk menciptakan keadilan dalam hal pemungutan pajak. Adil dalam perundang-undangan serta adil dalam pelaksanaannya.

2. Pemungutan pajak harus berdasarkan undang-undang (Syarat Yuridis)

Pajak diatur dalam UUD 1945 pasal 23 ayat 2, hal ini sebagai jaminan hukum untuk menyatakan keadilan, baik bagi negara maupun warganya.

3. Tidak mengganggu perekonomian (Syarat Ekonomis)

Pemungutan pajak diusahakan tidak menganggu kondisi perekonomian, baik dalam kegiatan produksi, perdagangan, maupun jasa. 


\section{JURNAL MEGA AKTIVA}

Email : megaaktiva@febi.umkendari.ac.id

Website : https://megaaktiva.umkendari.ac.id/index.php/Jurnal

4. Pemungutan pajak harus efisiensi (Syarat Finansiil)

Pemungutan pajak harus sesuai dengan fungsi budgetair, biaya-biaya yang dikeluarkan dalam melaksanakan pemungutan pajak harus diperhitungkan. Jangan sampai pajak yang diterima lebih rendah daripada biaya pengurusan pajak tersebut.

5. Sistem pemungutan pajak harus sederhana

Sistem pemungutan pajak yang sederhana akan memudahkan dan mendorong Wajib Pajak dalam memenuhi kewajiban perpajakannya.

\section{Timbul dan Hapusnya Utang Pajak}

Menurut Widyaningsih $(2013,20)$ timbulnya utang pajak diatur oleh dua ajaran:

1. Ajaran Formil

2. Ajaran Materiil

Hapusnya utang pajak dapat disebabkan beberapa hal:

1. Pembayaran

Utang pajak yang melekat pada Wajib Pajak akan secara otomatis terhapus bila ada aktifitas pembayaran kepada negara.

2. Kompensasi

Kompensasi terjadi bila Wajib Pajak memiliki tagihan berupa kelebihan pembayaran pajak. Jumlah kelebihan pembayaran pajak yang diterima Wajib Pajak sebelumnya harus dikompensasikan dengan pajak-pajak lainnya yang terutang.

3. Kadaluarsa

Kadaluarsa adalah salah satu sebab berakhirnya utang pajak dan hapusnya perikatan (hak untuk menagih atau kewajiban untuk membayar utang) karena telah lewat jangka waktunya, dan ditetapkan dalam Undang-Undang.

Hak untuk menagih pajak akan kadaluarsa apabila melampaui sepuluh tahun sejak saat terutangnya pajak atau berakhirnya masa pajak. Hal ini untuk memberikan kepastian hukum kapan utang pajak tidak dapat ditagih lagi.

4. Pembebasan

Utang pajak tidak berakhir dalam arti yang semestinya, tetapi karena ditiadakan.

Pembebasan ini berlaku terhadap sanksi administrasi saja bukan terhadap pokok pajaknya.

5. Penghapusan

Penghapusan utang pajak ini sama sifatnya dengan pembebasan, tetapi diberikan penghapusan dengan syarat bila keadaan keuangan Wajib Pajak sedang tidak memungkinkan.

\section{Hambatan Pemungutan Pajak}

Menurut Mardiasmo (2013, 8), hambatan terhadap pemungutan pajak dapat dikelompokkan menjadi:

1. Perlawanan pasif

Masyarakat tidak bersedia memenuhi kewajiban perpajakannya, sehingga dapat menyebabkan :

a. Perkembangan intelektual dan moral masyarakat

b. Sistem perpajakan yang sulit dipahami masyarakat

c. Sistem kontrol tidak dapat dilakukan atau dilaksanakan dengan baik

2. Perlawanan aktif 


\section{JURNAL MEGA AKTIVA}

Email : megaaktiva@febi.umkendari.ac.id

Website : https://megaaktiva.umkendari.ac.id/index.php/Jurnal

Perlawanan aktif meliputi semua usaha dan perbuatan yang secara langsung ditunjukan kepada fiskus dengan tujuan untuk menghindari pajak. Bentuknya antara lain :

a. Tax avoidance, usaha meringankan beban pajak dengan tidak melanggar undang-undang.

b. Tax evasion, usaha meringankan beban pajak dengan cara melanggar undangundang (menggelapkan pajak).

\section{Penagihan Pajak}

Pelaksanaan penagihan pajak yang tegas dan konsisten diharapkan dapat membawa pengaruh positif terhadap kepatuhan Wajib Pajak dalam membayarkan hutang pajaknya. Hal ini bertujuan untuk meningkatkan penerimaan Negara dari sektor pajak sehingga tindakan penagihan pajak tersebut dapat menyelamatkan penerimaan pajak yang tertunda. Dalam pelaksanaannya penagihan pajak berlandaskan pada peraturan perundangundangan yang berlaku, sehingga mempunyai kekuatan hukum baik bagi Wajib Pajak maupun aparatur pajaknya.

Dasar hukum melakukan tindakan penagihan pajak adalah Undang-undang No. 19 tahun 1997 tentang Penagihan Pajak dengan Surat Paksa. Undang-undang ini mulai berlaku pada tanggal 23 Mei 1997. Undang-undang ini kemudian diubah dengan Undangundang No.19 tahun 2000 yang mulai berlaku pada tanggal 1 Januari 2001.

Dalam Undang-Undang Nomor 19 Tahun 2000 tentang Penagihan Pajak Dengan Surat Paksa tertulis bahwa:

Penagihan pajak adalah serangkaian tindakan agar Penanggung Pajak melunasi utang pajak dan biaya penagihan pajak dengan menegur atau memperingatkan, melaksanakan penagihan seketika dan sekaligus, memberitahukan Surat Paksa, mengusulkan pencegahan, melaksanakan penyitaan, melaksanakan penyanderaan, menjual barang yang telah disita.

\section{Tindakan Penagihan Pajak}

Tindakan penagihan pajak dilakukan apabila pajak yang terutang sebagaimana tercantum dalam Surat Tagihan Pajak (STP), SKPKB, SKPKBT, Surat Keputusan Keberatan, Putusan Banding yang meyebabkan pajak yang harus dibayar bertambah, tidak atau kurang bayar setelah lewat tanggal jatuh tempo pembayaran pajak yang bersangkutan.

Dalam bidang administrasi perpajakan dikenal beberapa bentuk tindakan penagihan yaitu penagihan pasif, penagihan aktif dan penagihan dengan surat paksa.

1. Penagihan Pajak Pasif

Penagihan pajak pasif dilakukan dengan menggunakan Surat Tagihan Pajak (STP), Surat Ketetapan Pajak Kurang Bayar (SKPKB), Surat Ketetapan Pajak Kurang Bayar Tambahan (SKPKBT), Surat Keputusan Pembetulan, Surat Keputusan Keberatan, Surat Keputusan Banding yang menyebabkan pajak terutang menjadi lebih besar. (Suandy 2011, 169).

2. Penagihan Pajak Aktif

Penagihan pajak aktif merupakan kelanjutan dari penagihan pajak pasif, dimana dalam upaya penagihan pajak ini fiskus berperan aktif dalam arti tidak hanya mengirim 


$\int||$\begin{tabular}{c} 
JURNAL MEGA AKTIVA \\
$\begin{array}{c}\text { Email : } \text { megaaktiva@febi.umkendari.ac.id } \\
\text { Website }: \text { https://megaaktiva.umkendari.ac.id/index.php/Jurnal }\end{array}$ \\
\hline
\end{tabular}

Surat Tagihan atau Surat Ketetapan Pajak tetapi akan diikuti dengan tindakan sita, dan dilanjutkan dengan pelaksanaan lelang (Suandy 2011, 170).

\section{Fungsi Penagihan Pajak}

Fungsi penagihan pajak dibagi menjadi dua bagian, (Zuraida 2011, 38) yaitu:

1. Sebagai tindakan penegakan hukum kepada wajib pajak atau penanggung pajak untuk peraturan perundang-undangan.

2. Sebagai tindakan pengamanan penerimaan pajak.

\section{Surat Teguran}

Surat Teguran atau dapat juga disebut Surat Peringatan atau surat lain yang sejenis adalah surat yang diterbitkan oleh Pejabat untuk menegur atau memperingatkan kepada wajib Pajak untuk melunasi utang pajaknya. Langkah ini diambil sebagai peringatan agar penanggung pajak segera melunasi utang pajaknya untuk menghindari dilakukannya tindakan penagihan. Surat Teguran tersebut diterbitkan setelah lewat 7 hari dari tanggal jatuh tempo pembayaran (Widyaningsih 2013,308).

Tabel 1. Penyampaian Surat Teguran terhadap Keputusan Wajib Pajak Atas Surat Ketetapan Pajak

Keputusan Wajib Pajak atas Surat Ketetapan
Pajak

Penyampaian Surat Teguran

Setelah 7 hari sejak saat jatuh tempo pengajuan keberatan terlampaui

Setelah 7 hari sejak saat jatuh tempo pengajuan banding terlampaui

Setelah 7 hari sejak saat jatuh tempo pelunasan pajak yang masih harus dibayar berdasarkan Putusan Banding

Setelah 7 hari sejak saat jatuh tempo pelunasan surat ketetapan pajak 


\section{JURNAL MEGA AKTIVA}

Email : megaaktiva@febi.umkendari.ac.id

Website : https://megaaktiva.umkendari.ac.id/index.php/Jurnal

WP mencabut pengajuan keberatan atas SKPKB atau SKPKBT setelah tanggal jatuh tempo pelunasan tetapi sebelum tanggal terima Surat Pemberitahuan Untuk Hadir (SPUH) oleh WP

Penagihan Pajak atas utang PBB dan/atau BPHTB sebagaimana tercantum dalam:
a. STP PBB
b. Surat Ketetapan BPHTB Kurang Bayar
c. Surat Ketetapan BPHTB Kurang Bayar Tambahan
d. Surat Tagihan BPHTB
e. Surat Keputusan Pembetulan, Surat

Keputusan Keberatan, atau Putusan Banding yang menyebabkan jumlah pajak yang harus dibayar bertambah
Setelah 7 hari sejak tanggal pencabutan pengajuan keberatan

\begin{abstract}
Setelah 7 hari sejak tanggal jatuh tempo pelunasan surat ketetapan pajak atau surat keputusan
\end{abstract}

Sumber : Priantara 2013, 116

\section{Surat Paksa}

Surat Paksa merupakan surat keputusan yang mempunyai kekuatan yang sama dengan keputusan hakim dalam perkara perdata yang tidak dapat diganggu gugat lagi dengan cara meminta banding kepada hakim yang lebih atas. Jangka waktu penerbitan surat paksa adalah 1 bulan sejak tanggal diterbitkannya Surat Tagihan Pajak, Surat Ketetapan Pajak Kurang Bayar, Surat Ketetapan Pajak Kurang Bayar Tambahan, Surat Keputusan Pembetulan, Surat Keputusan Keberatan, Putusan Banding, dan Putusan Peninjauan Kembali atau 3 (tiga) bulan bagi Wajib Pajak di daerah tertentu.

\section{METODOLOGI PENELITIAN}

Penelitian ini adalah deskriptif kualitatif yang mengungkap fakta, fenomena, variabel dan keadaan yang terjadi saat penelitian berjalan dan menyajikan apa adanya. Objek penelitian yang dipilih dalam penelitian ini adalah Kantor Pelayanan Pajak (KPP) Pratama Jakarta Sawah Besar Satu yang berada di Jalan Kartini VIII No. 2, Jakarta Pusat. KPP Pratama Jakarta Sawah Besar Satu merupakan salah satu dari 22 tempat pelayanan administrasi pajak untuk kawasan Jakarta Pusat yang menyediakan layanan pelaporan pajak, pendaftaran NPWP, serta administrasi pajak lainnya. Data-data yang digunakan dalam penelitian ini adalah data primer dan sekunder. Teknik pengumpulan data yang digunakan dalam penelitian ini adalah studi kepustakaan dan studi lapangan yang meliputi observasi, wawancara dan dokumentasi.

\section{HASIL DAN PEMBAHASAN}

Penagihan Pajak dengan surat Teguran, surat Paksa, Sita dan Lelang oleh KPP Pratama Jakarta Sawah Besar Satu Sesuai UU No. 19 Tahun 2000

Berdasarkan uraian mengenai tata cara pelaksanaan penagihan pajak yang dilakukan oleh KPP Pratama Jakarta Sawah Besar Satu, maka pelaksanaan penagihan pajak dengan 
surat teguran,surat paksa, sita dan lelang tersebut telah sesuai dengan Ketentuan Perundang-Undangan Perpajakan, terutama Undang-Undang No. 19 Tahun 2000 Tentang Penagihan Pajak Dengan Surat Paksa. Dimana penagihan pajak dimulai dengan menegur dan memperingatkan, memberitahukan surat paksa, melakukan pemblokiran, mengusulkan pencegahan, melaksanakan penyanderaan, melaksanakan penyitaan dan menjual barang yang disita secara lelang. Kegiatan penagihan pajak ini dilakukan oleh seksi penagihan dengan pengawasan dari Kepala KPP Pratama Jakarta Sawah Besar Satu.

Kontribusi Penerimaan Penagihan Pajak dengan surat Teguran, surat Paksa, Sita dan Lelang Terhadap Pencairan Tunggakan Pajak di KPP Pratama Jakarta Sawah Besar Satu

Untuk mengukur seberapa besar kontribusi penerimaan tunggakan pajak yang berasal dari pencairan tunggakan pajak melalui penagihan pajak yang dilaksanakan oleh KPP Pratama Jakarta Sawah Besar Satu digunakan analisis rasio penerimaan tunggakan pajak dan dengan kriteria sebagai berikut:

$$
R P T P=\frac{\text { Pencairan Tunggakan Pajak }}{\text { Total Penerimaan Tunggakan Pajak }}
$$

Sumber: Seksi Penagihan KPP Pratama Jakarta Sawah Besar Satu

Tabel 2. Klasifikasi Kriteria Kontribusi

\begin{tabular}{cc}
\hline Persentase & Kriteria \\
\hline Lebih dari $50 \%$ & Sangat Baik \\
$40 \%-50 \%$ & Baik \\
$30 \%-40 \%$ & Sedang \\
$20 \%-30 \%$ & Cukup \\
$10 \%-20 \%$ & Kurang \\
$0 \%-10 \%$ & Sangat Kurang \\
\hline
\end{tabular}

Sumber : Peraturan Menteri Keuangan Nomor 249/PMK.02/2011 Tentang Pengukuran dan Evaluasi Kinerja atas Pelaksanaan Rencana Kerja dan Anggaran Kementerian Negara/Lembaga

\section{Kontribusi Penagihan Pajak melalui Surat Teguran}

Kontribusi penagihan pajak aktif melalui surat teguran diukur menggunakan analisis rasio penerimaan tunggakan pajak yaitu perbandingan antara pencairan tunggakan pajak melalui surat teguran dengan total penerimaan tunggakan pajak di KPP Pratama Jakarta Sawah Besar Satu. 
Email : megaaktiva@febi.umkendari.ac.id

Website : https://megaaktiva.umkendari.ac.id/index.php/Jurnal

Tabel 3. Hasil Perhitungan Kontribusi Penagihan Pajak Melalui Surat Teguran Tahun 2012-2015

\begin{tabular}{ccccc}
\hline Tahun & $\begin{array}{c}\text { Pencairan piutang } \\
(\mathbf{R p})\end{array}$ & $\begin{array}{c}\text { Total } \\
\text { penerimaan } \\
(\mathbf{R p})\end{array}$ & $\begin{array}{c}\text { Kontribusi } \\
(\mathbf{\%})\end{array}$ & Kriteria \\
\hline $\mathbf{2 0 1 2}$ & 5.064 .321 .327 & 14.637 .486 .594 & 34,60 & Sedang \\
$\mathbf{2 0 1 3}$ & 3.027 .886 .378 & 20.917 .620 .715 & 14,48 & Kurang \\
$\mathbf{2 0 1 4}$ & 8.507 .445 .988 & 14.921 .420 .569 & 57,01 & Sangat Baik \\
$\mathbf{2 0 1 5}$ & 13.529 .075 .204 & 47.768 .446 .048 & 28,32 & Cukup \\
\hline
\end{tabular}

Sumber : Data diolah 2016

\section{Kontribusi Penagihan Pajak Aktif melalui Surat Paksa}

Kontribusi penagihan pajak melalui surat paksa diukur menggunakan analisis rasio penerimaan tunggakan pajak yaitu perbandingan antara pencairan tunggakan pajak melalui surat paksa dengan total penerimaan tunggakan pajak di KPP Pratama Jakarta Sawah Besar Satu.

Tabel 4. Hasil Perhitungan Kontribusi Penagihan Pajak Melalui Surat Paksa Tahun 2012-2015

\begin{tabular}{ccccc}
\hline Tahun & $\begin{array}{c}\text { Pencairan Piutang } \\
(\mathbf{R p})\end{array}$ & $\begin{array}{c}\text { Total } \\
\text { Penerimaan } \\
(\mathbf{R p})\end{array}$ & $\begin{array}{c}\text { Kontribusi } \\
(\mathbf{\%})\end{array}$ & Kriteria \\
\hline $\mathbf{2 0 1 2}$ & 357.932 .877 & 14.637 .486 .594 & 2,45 & $\begin{array}{c}\text { Sangat } \\
\text { Kurang }\end{array}$ \\
$\mathbf{2 0 1 3}$ & 3.840 .972 .217 & 20.917 .620 .715 & 18,36 & Kurang \\
$\mathbf{2 0 1 4}$ & 4.168 .269 .585 & 14.921 .420 .569 & 27,93 & Cukup \\
$\mathbf{2 0 1 5}$ & 7.220 .837 .907 & 47.768 .446 .048 & 15,12 & Kurang \\
\hline
\end{tabular}

Sumber : Data diolah 2016

\section{Kontribusi Penagihan Pajak Aktif melalui Sita dan Lelang}

Kontribusi penagihan pajak melalui proses sita dan lelang diukur menggunakan analisis rasio penerimaan tunggakan pajak yaitu perbandingan antara pencairan tunggakan pajak melalui surat perintah melakukan penyitaan (SPMP) dengan total penerimaan tunggakan pajak di KPP Pratama Jakarta Sawah Besar Satu. 


\section{JURNAL MEGA AKTIVA}

Email : megaaktiva@febi.umkendari.ac.id

Website : https://megaaktiva.umkendari.ac.id/index.php/Jurnal

Tabel 5. Hasil Perhitungan Kontribusi Penagihan Pajak Melalui Sita dan Lelang Tahun 2012-2015

\begin{tabular}{ccccc}
\hline Tahun & $\begin{array}{c}\text { Pencairan Piutang } \\
(\mathbf{R p})\end{array}$ & $\begin{array}{c}\text { Total } \\
\text { Penerimaan } \\
(\mathbf{R p})\end{array}$ & $\begin{array}{c}\text { Kontribusi } \\
(\mathbf{\%})\end{array}$ & Kriteria \\
\hline $\mathbf{2 0 1 2}$ & - & 14.637 .486 .594 & 0 & $\begin{array}{c}\text { Sangat } \\
\text { Kurang }\end{array}$ \\
$\mathbf{2 0 1 3}$ & 306.355 .654 & 20.917 .620 .715 & 1,46 & $\begin{array}{c}\text { Sangat } \\
\text { Kurang }\end{array}$ \\
$\mathbf{2 0 1 4}$ & 2.245 .704 .996 & 14.921 .420 .569 & 15,05 & Kurang \\
$\mathbf{2 0 1 5}$ & 23.335 .947 .931 & 47.768 .446 .048 & 48,85 & Baik \\
\hline
\end{tabular}

Sumber : Data diolah 2016

Kendala dan Upaya Penagihan Pajak dengan surat Teguran, surat Paksa, Sita dan Lelang di KPP Pratama Jakarta Sawah Besar Satu

Dalam melaksanakan penagihan pajak banyak kendala yang sering dihadapi oleh KPP Pratama Jakarta Sawah Besar Satu. Misalnya seperti saat penyampaian surat paksa atau surat lainnya:

1. Wajib Pajak tidak dapat ditemukan di alamat yang tercatat dalam database atau master file KPP.

2. Adanya upaya perlawanan dari wajib pajak, baik perlawanan secara fisik maupun jalur hukum.

Meskipun banyak kendala yang di hadapi KPP Pratama Jakarta Sawah Besar Satu dapat mengatasi kendala tersebut dengan upaya-upaya seperti:

1. Dalam hal wajib pajak tidak dapat ditemukan karna pindah alamat.

Fiskus akan mencari informasi melalui lingkungan sekitar alamat wajib pajak tersebut, bertanya kepada tetangga atau RT/RW setempat.

2. Dalam hal wajib pajak mengupayakan perlawanan, baik secara fisik maupun jalur hukum.

Fiskus akan bekerja sama dengan institusi kepolisian untuk membantu dalam melaksanakan penagihan pajak dengan surat teguran, surat paksa, sita dan lelang.

\section{KESIMPULAN}

Tata cara pelaksanaan penagihan pajak dengan surat teguran, surat paksa, sita dan lelang di KPP Pratama Jakarta Sawah Besar Satu diawali dengan penerbitan surat teguran atas dasar surat ketetapan pajak (SKP/STP, SKPKB, SKPKBT, dsb) yang belum dilakukan pembayaran/pelunasan oleh wajib pajak sampai tanggal jatuh tempo. Berikut ini alur dan jadwal pelaksanaan penagihan pajak yang di lakukan oleh KPP Pratama Jakarta Sawah Besar Satu: (1) surat teguran, (2) surat paksa, (3) surat sita dan (4) lelang. Apabila setelah adanya surat sita wajib pajak tidak juga melunasi utang pajaknya dalam batas waktu 14 hari maka akan dilakukan pelelangan. Dalam tindakan lelang akan dilakukan pengumuman lelang terlebih dahulu. 


\section{JURNAL MEGA AKTIVA}

Email : megaaktiva@febi.umkendari.ac.id

Website : https://megaaktiva.umkendari.ac.id/index.php/Jurnal

1. Pelaksanaan penagihan pajak dengan surat teguran, surat paksa, sita dan lelang yang dilakukan oleh KPP Pratama Jakarta Sawah Besar satu sudah sesuai dengan UU No. 19 Tahun 2000 (UU PPSP) dimana penagihan pajak aktif dimulai dengan menegur dan memperingatkan, memberitahukan surat paksa, melakukan pemblokiran, mengusulkan pencegahan, melaksanakan penyanderaan, melaksanakan penyitaan dan menjual barang yang disita secara lelang.

2. Besarnya kontribusi penerimaan penagihan pajak dengan surat teguran, surat paksa, sita dan lelang terhadap pencairan tunggakan pajak di KPP Pratama Jakarta Sawah Besar Satu adalah sebagai berikut:

a. Kontribusi penerimaan pajak dari surat teguran pada tahun 2012 tergolong dalam kriteria sedang, tahun 2013 kurang, tahun 2014 sangat baik dan tahun 2015 cukup.

b. Kontribusi penerimaan pajak dari surat paksa pada tahun 2012 tergolong dalam kriteria sangat kurang, tahun 2013 kurang, tahun 2014 cukup dan tahun 2015 kurang baik.

c. Kontribusi penerimaan pajak dari sita dan lelang pada tahun 2012 tergolong dalam kriteria sangat kurang, tahun 2013 sangat kurang, tahun 2014 kurang dan tahun 2015 baik.

3. Kendala dan upaya penagihan pajak dengan surat teguran, surat paksa, sita dan lelang di KPP Pratama Jakarta Sawah Besar Satu yaitu:

a. Wajib Pajak tidak dapat ditemukan di alamat yang tercatat dalam database atau master file KPP. Dalam hal ini Fiskus akan mencari informasi melalui lingkungan sekitar alamat wajib pajak tersebut, bertanya kepada tetangga atau RT/RW setempat.

b. Adanya upaya perlawanan dari wajib pajak, baik perlawanan secara fisik maupun jalur hukum. Dalam hal ini Fiskus akan bekerja sama dengan institusi kepolisian untuk membantu dalam melaksanakan penagihan surat teguran, surat paksa, sita dan lelang.

\section{DAFTAR PUSTAKA}

Destriyatna, Gilang. 2014. "Efektivitas Penagihan Pajak dengan Surat Teguran, Surat Paksa dan Penyitaan dalam Mengoptimalkan Penerimaan Pajak di Kantor Pelayanan Pajak Pratama Malang Selatan”. Jurnal Perpajakan Vol. 3 No. 1, Hal. 1-9.

Ilyas, Wirawan B, dan Richard Burton. 2010. Hukum Pajak (Edisi Revisi). Jakarta: Salemba Empat.

Kusumo, Rifari Widya. 2013. "Efektivitas Penagihan Pajak dengan Surat Paksa dan Penyitaan dalam Upaya Optimalisasi Penerimaan Pajak". Jurnal Mahasiswa Fakultas Hukum. Malang: Universitas Brawijaya.

Mardiasmo. 2013. Perpajakan Edisi Revisi. Yogyakarta: Andi.

Paseleng, Agustinus, dkk. 2013. "Efektivitas Penagihan Pajak dengan Surat Teguran dan Surat Paksa terhadap Penerimaan Pajak Penghasilan pada Kantor Pelayanan Pajak Pratama Manado". Jurnal EMBA Vol. 1 No.4, Hal. 2371-2381.

Pohan, Chairil Anwar. 2014. Perpajakan Indonesia Teori dan Kasus. Jakarta: Mitra Wacana Media. 


\section{JURNAL MEGA AKTIVA}

Email : megaaktiva@febi.umkendari.ac.id

Website : https://megaaktiva.umkendari.ac.id/index.php/Jurnal

Peraturan Menteri Keuangan Nomor 85/PMK.03/2010 Tentang Perubahan Atas Peraturan Menteri Keuangan Nomor 24/PMK.03/2008 Tentang Tata Cara Pelaksanaan Penagihan Dengan Surat Paksa Dan Pelaksanaan Penagihan Seketika Dan Sekaligus.

Peraturan Pemerintah Nomor 74 Tahun 2011 Tentang Tata Cara Pelaksanaan Hak Dan Pemenuhan Kewajiban Perpajakan.

Peraturan Pemerintah Nomor 135 Tahun 2000 Tentang Tata Cara Penyitaan Dalam Rangka Penagihan Pajak Dengan Surat Paksa.

Peraturan Pemerintah Nomor 136 Tahun 2000 Tentang Tata Cara Penjualan Barang Sitaan Yang Dikecualikan Dari Penjualan Secara Lelang Dalam Rangka Penagihan Pajak Dengan Surat Paksa.

Priantara, Diaz. 2013. Perpajakan Indonesia. Jakarta: Mitra Wacana Media.

Rifqiansyah,Hasbi, dkk. 2014. “Analisis Efektivitas dan Kontribusi Penagihan Pajak Aktif terhadap Pencairan Tunggakan Pajak (Studi pada Kantor Pelayanan Pajak Pratama Malang Utara)". Jurnal Administrasi Bisnis Vol. 15 No. 1, Hal. 1-10.

Suandy, Erly. 2011. Hukum Pajak (Edisi 5). Jakarta: Salemba Empat.

Sumarsan, Thomas. 2015. Perpajakan Indonesia. Jakarta: PT Indeks.

Sutanto, Paojan Mas'ud. 2014. Perpajakan Indonesia (Teori dan Aplikasi). Jakarta: Mitra Wacana Media.

Tunas, Derlina Sutria. 2013. "Efektivitas Penagihan Tunggakan Pajak dengan menggunakan Surat Paksa pada Kantor Pelayanan Pajak Pratama Manado". Jurnal EMBA Vol. 1 No. 4, Hal. 1520-1531.

Undang-Undang Republik Indonesia Nomor 16 Tahun 2009 Tentang Perubahan Keempat Atas Undang-Undang Nomor 6 Tahun 1983 Tentang Ketentuan Umum Dan Tata Cara Perpajakan.

Undang-Undang Republik Indonesia Nomor 19 Tahun 2000 Tentang Perubahan Atas Undang-Undang Nomor 19 Tahun 1997 Tentang Penagihan Pajak Dengan Surat Paksa.

Waluyo. 2013. Perpajakan Indonesia (Edisi 11). Jakarta: Salemba Empat.

Widyaningsih, Aristanti. 2013. Hukum Pajak dan Perpajakan. Bandung: Alfabeta.

Zuraida, Ida. 2011. Penagihan Pajak. Bogor: Ghalia Indonesia. 